\title{
Influence of static mean stresses on the fatigue behavior of 2024 aluminum alloy under multiaxial loading
}

\author{
A.S. Yankin, V.E. Wildemann, N.S. Belonogov, O.A. Staroverov \\ Center of Experimental Mechanics, Perm National Research Polytechnic University, Perm, Russian Federation \\ yas.cem@yandex.ru, https://orcid.org/0000-0002-0895-4912 \\ wildemann@pstu.ru, bttps://orcid.org/0000-0002-6240-4022 \\ cem.belonogov@gmail.com \\ cem_staroverov@mail.ru, bttps://orcid.org/0000-0001-6095-0962
}

\begin{abstract}
Axial alternating stress controlled fatigue tests with superimposed static torsional mean stress and shear alternating fatigue tests with superimposed static tensile mean stress are represented. The material used in the current experimental investigation is 2024 aluminum alloy. A decrease in the fatigue life of the material was observed with an increase in the shear and static tensile stresses. Marin and modified Crossland methods are analyzed by means of the available experimental data. The two modifications of Sines method are proposed to take into account the static torsional stress effect (Sines + ) and different slopes of the S-N curves in tension-compression and torsion tests (Sines ++ ). It is shown that Sines ++ model is the most accurate among others.
\end{abstract}

KEYwORDs. Multiaxial fatigue; Mean stress; Multiaxial fatigue criteria; 2024 aluminum alloy.

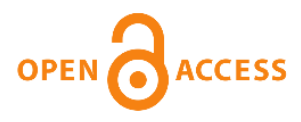

Citation: Yankin, A.S., Wildemann, V.E., Belonogov, N.S., Staroverov, O.A., Influence of static mean stresses on the fatigue behavior of 2024 aluminum alloy under multiaxial loading, Frattura ed Integrità Strutturale, 51 (2020) 151-163.

Received: 30.09 .2019

Accepted: 07.11 .2019

Published: 01.01.2020

Copyright: (C) 2020 This is an open access article under the terms of the CC-BY 4.0, which permits unrestricted use, distribution, and reproduction in any medium, provided the original author and source are credited.

\section{INTRODUCTION}

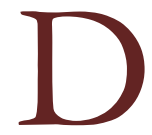

uring operations the greatest number of critical components of construction elements undertake complex cyclic loadings, thus the estimation of their influence on durability of metal materials is a problem to be solved [1-5]. Also, the need in studying fatigue processes under complex stress state brought a number of experimental works in this area, which used specialized equipment and methods of multiaxial loading. Here are some major research centers studying the problems of multiaxial fatigue: ENSAM University in Bordeaux, France (T. Palin-Luc, N. Saintier, F. Morel) [6, 7], University of Opole, Poland (T. Lagoda) [8], University of Sheffield, United Kingdom (L. Sumsel) [9], University of Lisbon, Portugal (V. Anes, L. Reis, M de Freitas) [10, 11], S.P. Timoshenko Institute of Mechanics, Kiev, Ukraine (V.P. Golub) [12], Ishlinsky Institute for Problems in Mechanics RAS, Moscow, Russia (N.G. Burago, A.B. Zhuravlev, I.S. Nikitin) [13, 14], and others [15]. 
The main loading conditions referred to the literature when studying multiaxial fatigue are biaxial tension of cross-shaped specimens, tension with torsion and bending with torsion of cylindrical specimens. Meanwhile attention is paid not only to the proportional cyclic loading but also to more complex modes with phase shifting, different frequencies and other characteristics [16-20]. Apart from testing standard hourglass and tubular specimens, one can also test weld joint specimens $[21,22]$, specimens with grooves [23] and other stress raisers [24].

Cyclic effects may be associated with a cycle asymmetry due to static loadings caused, as an example, by gravity force or linear overloading. Apart from that, static loads may occur along an axis different from the cyclic ones, which results in bending cyclic loads with constant torsion and so on. Gerber [25], Goodman [26], Morrow [27], Smith [28], Oding [29], Birger [30] and many others [31-35] studied the influence of the asymmetry of the loading cycle on the fatigue behavior of various materials. As a rule, the experimental results are shown in the Haigh diagram (the stress amplitude versus the mean stress in the cycle), and different relations for their description are suggested. An increase of the mean stress leads to a decrease of fatigue strength. This effect is quite strong for brittle materials (e.g. cast iron) both in axial and in torsion [34]. However this effect is lower in torsion than in axial for ductile materials such as steels and aluminum alloys [31]. Thus, some authors [5, 36, 37] do not suggest taking into account the influence of the mean stress under torsion until the maximum values of shear stress do not exceed yield strength. Let us note that under cyclic loadings in the compression area there is an increase in fatigue strength which is more significant for brittle materials and less significant for ductile ones [5, 32].

In general, a similar behavior is demonstrated by the materials under constant static stresses under multiaxial loadings (e.g. an alternating bending with a constant torsion and so on) [5, 36-39]. However, there are much less studies in this area, compared to uniaxial effects, and there is no complex approach to studying this issue. Apart from that, works mostly pay attention to fatigue limit under more than 106 cycles, i.e. they consider such loadings that allow a material (conventionally) to endure an unlimited number of loading cycles. But if we design structures with a set (limited) service life in order to save resources, it is important to describe not only the fatigue limit but also S-N curves at different levels of additional static stresses.

In the previous work [40] the authors researched the influence of the constant components of multiaxial loading (constant tension and alternating torsion, constant torsion and alternating tension-compression) on the fatigue life of 2024 aluminum alloy. It is shown that the influence of the constant static stresses results in a decrease of the number of cycles to failure. Moreover, the realized values of the constant static stresses obviously did not exceed the corresponding values of the conventional yield strength for the alloy. The purpose of this work is to check if it is reasonable to use various criteria for multiaxial fatigue using the experimental data presented in the article [40].

\section{EXPERIMENTS}

\section{Material and specimen}

7 he material used in the current experimental investigation is a common aeronautic material, 2024 aluminum alloy. The chemical composition of the alloy consists of $\mathrm{Cu} 4.28, \mathrm{Mg}$ 1.48, $\mathrm{Mn} 0.75$, Fe 0.28, Si 0.29, Zn 0.12, Ni 0.009, Ti 0.06, Cr 0.017, $\mathrm{Pb} 0.05$. Mechanical properties for the material are listed in Tab. 1. Fatigue tests were performed on hourglass specimens. The specimen geometry is shown in Fig. 1. The specimens are designed in accordance with recommendations of national standard GOST 25.502. Stresses used in calculating were in accordance with the minimum cross-section of specimen.

\begin{tabular}{cccc}
\hline Property & Symbol & 2024 aluminum alloy & Unit \\
$0.2 \%$ Tensile yield strength & $\sigma_{y}$ & 336 & $\mathrm{MPa}$ \\
$0.3 \%$ Torsional yield strength & $\tau_{y}$ & 153 & $\mathrm{MPa}$ \\
Ultimate tensile strength & $\sigma_{u}$ & 450 & $\mathrm{MPa}$ \\
Modulus of elasticity & $E$ & 75.4 & $\mathrm{GPa}$ \\
Shear modulus & $G$ & 30.0 & $\mathrm{GPa}$ \\
\hline
\end{tabular}

Table 1: Mechanical properties of 2024 aluminum alloy. 


\begin{tabular}{|c|c|c|c|c|c|}
\hline Loading path & $\sigma_{a}(\mathrm{MPa})$ & $\sigma_{\mathrm{m}}(\mathrm{MPa})$ & $\tau_{a}(\mathrm{MPa})$ & $\tau_{\mathrm{m}}(\mathrm{MPa})$ & $N$ \\
\hline Uniaxial & 168.1 & 0 & 0 & 0 & 476451 \\
\hline TSTS1 & 168.1 & 0 & 0 & 15.3 & 378142 \\
\hline TSTS1 & 168.1 & 0 & 0 & 30.6 & 435758 \\
\hline TSTS1 & 168.1 & 0 & 0 & 30.6 & 404964 \\
\hline TSTS1 & 168.1 & 0 & 0 & 45.9 & 356718 \\
\hline TSTS1 & 168.1 & 0 & 0 & 45.9 & 368430 \\
\hline TSTS1 & 168.1 & 0 & 0 & 76.5 & 203836 \\
\hline TSTS1 & 168.1 & 0 & 0 & 76.5 & 298301 \\
\hline TSTS1 & 168.1 & 0 & 0 & 91.8 & 255564 \\
\hline TSTS1 & 168.1 & 0 & 0 & 91.8 & 322877 \\
\hline TSTS1 & 168.1 & 0 & 0 & 107.1 & 240549 \\
\hline TSTS1 & 168.1 & 0 & 0 & 107.1 & 296235 \\
\hline Uniaxial & 205.1 & 0 & 0 & 0 & 165011 \\
\hline TSTS1 & 205.1 & 0 & 0 & 18.4 & 196496 \\
\hline TSTS1 & 205.1 & 0 & 0 & 18.4 & 182057 \\
\hline TSTS1 & 205.1 & 0 & 0 & 36.8 & 120610 \\
\hline TSTS1 & 205.1 & 0 & 0 & 36.8 & 166584 \\
\hline TSTS1 & 205.1 & 0 & 0 & 55.2 & 155908 \\
\hline TSTS1 & 205.1 & 0 & 0 & 55.2 & 133260 \\
\hline TSTS1 & 205.1 & 0 & 0 & 73.6 & 158711 \\
\hline TSTS1 & 205.1 & 0 & 0 & 73.6 & 179106 \\
\hline TSTS1 & 205.1 & 0 & 0 & 92.0 & 122202 \\
\hline TSTS1 & 205.1 & 0 & 0 & 92.0 & 121562 \\
\hline TSTS1 & 205.1 & 0 & 0 & 110.4 & 126479 \\
\hline TSTS1 & 205.1 & 0 & 0 & 110.4 & 207306 \\
\hline TSTS2 & 0 & 67.3 & 107.1 & 0 & 68057 \\
\hline TSTS2 & 0 & 67.3 & 107.1 & 0 & 139743 \\
\hline TSTS2 & 0 & 100.9 & 107.1 & 0 & 74294 \\
\hline TSTS2 & 0 & 100.9 & 107.1 & 0 & 45391 \\
\hline TSTS2 & 0 & 134.5 & 107.1 & 0 & 34385 \\
\hline TSTS2 & 0 & 134.5 & 107.1 & 0 & 37224 \\
\hline TSTS2 & 0 & 201.8 & 107.1 & 0 & 35651 \\
\hline TSTS2 & 0 & 201.8 & 107.1 & 0 & 27162 \\
\hline Torsion & 0 & 0 & 114.8 & 0 & 115648 \\
\hline Torsion & 0 & 0 & 114.8 & 0 & 99285 \\
\hline TSTS2 & 0 & 16.8 & 114.8 & 0 & 83350 \\
\hline TSTS2 & 0 & 16.8 & 114.8 & 0 & 86779 \\
\hline TSTS2 & 0 & 33.6 & 114.8 & 0 & 59443 \\
\hline TSTS2 & 0 & 33.6 & 114.8 & 0 & 95959 \\
\hline TSTS2 & 0 & 67.3 & 114.8 & 0 & 49145 \\
\hline TSTS2 & 0 & 67.3 & 114.8 & 0 & 64942 \\
\hline TSTS2 & 0 & 100.9 & 114.8 & 0 & 35866 \\
\hline TSTS2 & 0 & 100.9 & 114.8 & 0 & 16966 \\
\hline TSTS2 & 0 & 201.8 & 114.8 & 0 & 24661 \\
\hline TSTS2 & 0 & 201.8 & 114.8 & 0 & 19823 \\
\hline
\end{tabular}

Table 2: Summary fatigue tests. 


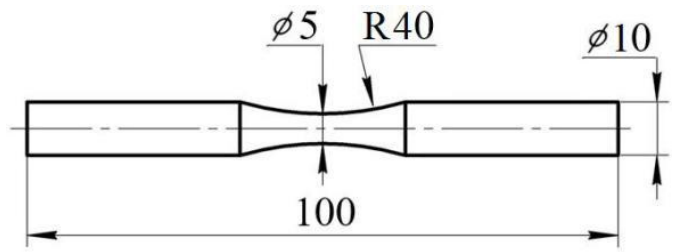

Figure 1: Specimen geometry, all dimensions in millimeters.

\section{Experimental procedure and results}

All tests were carried out in the Instron ElectroPuls E10000 at room temperature in Center of Experimental Mechanics (Russia). The ElectroPuls E10000 Linear-Torsion is an all-electric test instrument with a dynamic linear load capacity of $\pm 10 \mathrm{kN}$ and dynamic torque capacity of $\pm 100 \mathrm{Nm}$. A summary of the applied loading conditions and experimental fatigue life for each test performed is included in Tab. 2.

All tests were performed in load-control, using sinusoidal waveforms, and include uniaxial (6 tests), pure torsion (4 tests), tension with static torsional stress (30 tests), and torsion with static tensile stress (22 tests) loading conditions. The range of the torsional mean stress $\tau_{m}$ was from 0 to $0.84 \cdot \tau_{y}$. The normal stress amplitudes $\sigma_{a}$ were $0.5 \cdot \sigma_{y}$ and $0.61 \cdot \sigma_{y}$. The testing frequency was $50 \mathrm{~Hz}$.

$$
\left\{\begin{array}{l}
\sigma=\sigma_{a} \sin (2 \pi v t) \\
\tau=\tau_{m}
\end{array}\right.
$$

The range of the static tensile stress $\sigma_{\mathrm{m}}$ was from 0 to $0.6 \cdot \sigma_{y}$. The shear stress amplitudes $\tau_{a}$ were $0.7 \cdot \tau_{y}$ and $\tau_{a}=0.75 \cdot \tau_{y}$. The testing frequency was $3.4 \mathrm{~Hz}$.

$$
\left\{\begin{array}{l}
\tau=\tau_{a} \sin (2 \pi v t) \\
\sigma=\sigma_{m}
\end{array}\right.
$$

During the experiments, a decrease in the fatigue life of the material was observed with an increase in the static torsional and tensile stresses. At smaller values of the stress amplitude in the cycle, a decrease in fatigue life with an increase in the static stresses is more evident.

\section{CORRELATION OF THE EXPERIMENTAL RESULTS WITH MULTIAXIAL FATIGUE MODELS}

A $\mathrm{s}$ has been pointed out before the static torsional stress effect less pronounced than the static tensile stress effect in ductile metals. Some researchers $[5,36,37]$ propose to neglect this effect as long as the maximum shear stress is within the torsional yield strength (models Sines [5], Crossland [41] and so on). Relevant results of the literature show that the static torsional stress effect is not negligible in ductile metals.

\section{The Marin method}

The Marin method [42] can be expressed through Eqn. (3):

$$
\begin{aligned}
& \left(\frac{\sqrt{3} \sqrt{I_{2 a}}}{\sigma_{-1}}\right)^{2}+\left(\frac{\sqrt{3} \sqrt{I_{2 m}}}{\sigma_{u}}\right)^{2} \leq 1 \\
& \sqrt{I_{2 a}}=\frac{1}{\sqrt{6}} \sqrt{\left(\sigma_{11 a}-\sigma_{22 a}\right)^{2}+\left(\sigma_{22 a}-\sigma_{33 a}\right)^{2}+\left(\sigma_{11 a}-\sigma_{33 a}\right)^{2}+6\left(\tau_{12 a}^{2}+\tau_{23 a}^{2}+\tau_{13 a}^{2}\right)}
\end{aligned}
$$




$$
\sqrt{I_{2 m}}=\frac{1}{\sqrt{6}} \sqrt{\left(\sigma_{11 m}-\sigma_{22 m}\right)^{2}+\left(\sigma_{22 m}-\sigma_{33 m}\right)^{2}+\left(\sigma_{11 m}-\sigma_{33 m}\right)^{2}+6\left(\tau_{12 m}^{2}+\tau_{23 m}^{2}+\tau_{13 m}^{2}\right)}
$$

where $\sigma_{-1}$ is the fully reversed axial fatigue limit, $\sigma_{u}$ is the ultimate tensile strength, $I_{2 a}$ and $I_{2 m}$ are the amplitude and the mean value of the second invariant of the stress deviator tensor.

In order to predict the material fracture with an arbitrary number of $N$ cycles, let us replace the fully reversed axial fatigue limit $\sigma_{-1}$ in Eqn. (3) with the axial S-N curve $\sigma_{a 0(N)}$.

$$
\left(\frac{\sqrt{3} \sqrt{I_{2 a}}}{\sigma_{a 0}(N)}\right)^{2}+\left(\frac{\sqrt{3} \sqrt{I_{2 m}}}{\sigma_{u}}\right)^{2} \leq 1
$$

Let us rearrange Eqn. (3) for two types of multiaxial loadings given in the second part. For the first case (see Eq (1)), we will write as follows

$$
\sqrt{I_{2 a}}=\sigma_{a} / \sqrt{3}, \sqrt{I_{2 m}}=\tau_{m}, \sigma_{a} \leq \sigma_{a 0}(N) \sqrt{1-\left(\frac{\sqrt{3} \tau_{m}}{\sigma_{u}}\right)^{2}}
$$

For the second one (see Eq 2), it will be

$$
\sqrt{I_{2 a}}=\tau_{a}, \sqrt{I_{2 m}}=\sigma_{m} / \sqrt{3}, \tau_{a} \leq \frac{\sigma_{a 0}(N)}{\sqrt{3}} \sqrt{1-\left(\frac{\sigma_{m}}{\sigma_{u}}\right)^{2}}
$$

The Marin method requires the ultimate tensile strength and the axial S-N curve. The ultimate tensile strength $\sigma_{u}$ of the alloy is equal to $450 \mathrm{MPa}$. The axial S-N curve was plotted according to the experimental data $\left(\sigma_{a}=0.5 \cdot \sigma_{y} ; \quad \tau_{\mathrm{m}}=0\right.$ and $\sigma_{a}=0.61 \cdot \sigma_{j} ; \tau_{\mathrm{m}}=0$ from Tab. 2) and was interpolated through a function $\sigma_{a 0}(N)$.

$$
\begin{gathered}
\sigma_{a 0}(N)=\sigma_{f}^{\prime}(2 N)^{\beta} \\
\tau_{a 0}(N)=\tau_{f}^{\prime}(2 N)^{\beta_{0}}
\end{gathered}
$$

where coefficients $\sigma_{f}^{\prime}=1478 \mathrm{MPa}, \tau_{f}^{\prime}=370 \mathrm{MPa}$, and exponents $\beta=-0.156, \beta_{0}=-0.051$.

For different alloys one can observe an increase of fatigue strength in the compression area (at negative static tensile stresses $\sigma_{\mathrm{m}}$ ) [32]. However, the Marin method (see Eq 6) does not make it possible to consider this. One can observe the same value of the second invariant $I_{2 \mathrm{~m}}$ (see Eq 5) at positive and negative values of static tensile stresses $\sigma_{\mathrm{m}}$.

Also, the disadvantage of the method is that it predicts the same reduction of fatigue life at constant torsional $\tau_{\mathrm{m}}$ and tensile $\sigma_{\mathrm{m}}$ mean stresses (see Eq 6). And, as has been mentioned above, for ductile materials an increase of the mean stress in torsion direction leads to a decrease of fatigue strength lower than in axial direction. In order to take into account this effect one can add, for example, the maximum hydrostatic stress (see Eq 11) how was made in [31].

The advantage of the model is its relative simplicity and a small number of adjusting experiments $\left(\sigma_{u} ; \sigma_{a 0}(N)\right)$ necessary to determine its parameters.

\section{The modified Crossland method (Crossland + )}

The Crossland method does not take into account the static torsional stress effect. Therefore, authors in Ref. [31] proposed the modified Crossland method: 


$$
\begin{aligned}
& \sqrt{\left(\frac{\sqrt{I_{2 a}}}{a}\right)^{2}+\left(\frac{\sqrt{I_{2 m}}}{b}\right)^{2}}+\frac{\sigma_{H \max }}{c} \leq 1 \\
& \sigma_{H \max }=\frac{1}{3}\left(\sigma_{11 \max }+\sigma_{22 \max }+\sigma_{33 \max }\right)
\end{aligned}
$$

where $\sigma_{H \max }$ is the maximum hydrostatic stress, $a, b, c$ are the model parameters, which were determined as follows: - the parameter $a$ was determined by means of the torsional S-N curve $\tau_{a 0}(N)$

$$
\begin{aligned}
& \sigma_{a}=\sigma_{m}=\tau_{m}=0, \sigma_{H \max }=0, \sqrt{I_{2 m}}=0, \tau_{a}=\tau_{a 0}(N), \sqrt{I_{2 a}}=\tau_{a 0}(N) \\
& a=\tau_{a 0}(N)
\end{aligned}
$$

- the parameter $c$ was determined by means of the axial S-N curve $\sigma_{a 0}(N)$

$$
\begin{aligned}
& \tau_{a}=\sigma_{m}=\tau_{m}=0, \sqrt{I_{2 m}}=0, \sigma_{a}=\sigma_{a 0}(N), \sqrt{I_{2 a}}=\frac{1}{\sqrt{3}} \sigma_{a 0}(N), \sigma_{H \max }=\frac{1}{3} \sigma_{a 0}(N) \\
& c=\frac{\sigma_{a 0}(N)}{3-\sqrt{3} \sigma_{a 0}(N) / a}
\end{aligned}
$$

- the parameter $b$ was determined by means of the axial S-N curve $\sigma_{a \tau}(N)$ with torsional mean stress $\tau_{\mathrm{m}}=126 \mathrm{MPa}$

$$
\begin{aligned}
& \tau_{a}=\sigma_{m}=0, \sqrt{I_{2 m}}=\tau_{m}, \sigma_{a}=\sigma_{a \tau}(N), \sqrt{I_{2 a}}=\frac{1}{\sqrt{3}} \sigma_{a \tau}(N), \sigma_{H \max }=\frac{1}{3} \sigma_{a \tau}(N) \\
& b=\frac{\tau_{m}}{\sqrt{\left(1-\frac{\sigma_{a \tau}(N)}{3 c}\right)^{2}-\left(\frac{\sigma_{a \tau}(N)}{\sqrt{3} a}\right)^{2}}}
\end{aligned}
$$

S-N curves $\tau_{a 0}(N)$ and $\sigma_{a \tau}(N)$ were plotted according to the experimental data from Tab. 2 similarly to curve $\sigma_{a 0}(N)$ (see section 3.1, Eq (9)).

The advantage of this model is that it takes into account the beneficial effect of the mean compressive axial stresses and that the Marin method does not predict. Also, by using the $\sigma_{H \max }$ term in the multiaxial function (11), the mean stress effect in the axial direction is increased compared with the torsion case. It is worth notice that this method is quite complicated, compared to the Marin method, and requires a great number of adjusting experiments (at least three S-N curves $\tau_{a 0}(N), \sigma_{a 0}(N)$ and $\left.\sigma_{a \tau}(N)\right)$.

\section{EXTENSION OF THE SINES METHOD}

Extension of the Sines method to take into account the static torsional mean stress effect (Sines + )

7 he Sines method [5] can be expressed through Eqn. (19): 


$$
\begin{aligned}
& \frac{\sqrt{I_{2 a}}}{A_{0}}+\frac{I_{1 m}}{B_{0}} \leq 1 \\
& \quad I_{1 m}=\sigma_{11 m}+\sigma_{22 m}+\sigma_{33 m}
\end{aligned}
$$

where $I_{1 \mathrm{~m}}$ is the mean value of the first invariant of the stress tensor, $A_{0}$ and $B_{0}$ are the model parameters. In this article the Eqn. (19) was modified similarly to the modified Crossland method [31] to take into account the static torsional stress effect

$$
\sqrt{\left(\frac{\sqrt{I_{2 a}}}{A_{1}}\right)^{2}+\left(\frac{\sqrt{I_{2 m}}}{B_{1}}\right)^{2}}+\frac{I_{1 m}}{C_{1}} \leq 1
$$

where $A_{1}, B_{1}$ and $C_{1}$ are the model parameters, which were determined as follows:

- the parameter $A_{1}$ was determined by means of the axial S-N curve $\sigma_{a 0}(N)$

$$
\begin{aligned}
& \tau_{a}=\sigma_{m}=\tau_{m}=0, \sqrt{I_{2 m}}=0, I_{1 m}=0, \sigma_{a}=\sigma_{a 0}(N), \sqrt{I_{2 a}}=\frac{1}{\sqrt{3}} \sigma_{a 0}(N) \\
& A_{1}=\frac{1}{\sqrt{3}} \sigma_{a 0}(N)
\end{aligned}
$$

- the parameter $B_{1}$ was determined by means of the axial S-N curve $\sigma_{a \tau}(N)$ with torsional mean stress $\tau_{\mathrm{m}}=126 \mathrm{MPa}$

$$
\begin{aligned}
& \sqrt{I_{2 m}}=\tau_{m}, \tau_{a}=\sigma_{m}=0, I_{1 m}=0, \sigma_{a}=\sigma_{a \tau}(N), \sqrt{I_{2 a}}=\frac{1}{\sqrt{3}} \sigma_{a \tau}(N) \\
& B_{1}=\frac{\tau_{m}}{\sqrt{1-\left(\frac{\sigma_{a \tau}(N)}{\sqrt{3} A_{1}}\right)^{2}}}
\end{aligned}
$$

- the parameter $C_{1}$ was determined by means of the torsional S-N curve $\tau_{a \sigma}(N)$ with tensile mean stress $\sigma_{\mathrm{m}}=202 \mathrm{MPa}$

$$
\begin{aligned}
\sigma_{a} & =\tau_{m}=0, \sqrt{I_{2 m}}=\frac{1}{\sqrt{3}} \sigma_{m}, I_{1 m}=\sigma_{m}, \tau_{a}=\tau_{a \sigma}(N), \sqrt{I_{2 a}}=\tau_{a \sigma}(N) \\
C_{1} & =\frac{\sigma_{m}}{1-\sqrt{\left(\frac{\tau_{a \sigma}(N)}{A_{1}}\right)^{2}+\left(\frac{\sigma_{m}}{\sqrt{3} B_{1}}\right)^{2}}}
\end{aligned}
$$

S-N curve $\tau_{a \sigma}(N)$ were plotted according to the experimental data from Tab. 2 similarly to curve $\sigma_{a 0}(N)$ (see section 3.1). This model has all the advantages and disadvantages of the previous modified Crossland method.

Extension of the Sines method to take into account different slopes of the S-N curves under tension-compression and torsion (Sines ++ ) In some cases, experiments show different slope of the S-N curves in tension-compression $\sigma_{a 0}(N)$ and torsion $\tau_{a 0}(N)$ tests. It means that the ratio $\sigma_{a 0}\left(N_{i}\right) / \tau_{a 0}\left(N_{i}\right)$ will not be constant. The modified Sines method (Sines +$)$ does not take 
into account this effect because it predicts the constant ratio $\sigma_{a 0}\left(N_{i}\right) / \tau_{a 0}\left(N_{i}\right)=\sqrt{ }$ 3. Therefore, the Eqn. (21) was modified as follows:

$$
\begin{aligned}
& \sqrt{\left(A_{2} \sqrt{I_{2 a}}\right)^{2}+\left(B_{2} \sqrt{I_{2 m}}\right)^{2}}+C_{2} I_{1 m}+D_{2} I_{1 a} \leq 1 \\
& I_{1 a}=\sigma_{11 a}+\sigma_{22 a}+\sigma_{33 a}
\end{aligned}
$$

The parameters of Eqn. (28) are written in the numerator. It helps avoiding the division by zero (function jumps) at $N_{k}$ point, when $\sigma_{a 0}\left(N_{k}\right) / \tau_{a 0}\left(N_{k}\right)=\sqrt{ } 3$. We think that such a formulation is more convenient for program implementation. The the model parameters $A_{2}, B_{2}, C_{2}$ and $D_{2}$ were determined as follows:

- the parameter $A_{2}$ was determined by means of the torsional S-N curve $\tau_{a 0}(N)$

$$
\begin{aligned}
& \sigma_{a}=\sigma_{m}=\tau_{m}=0, \sqrt{I_{2 m}}=0, I_{1 m}=0, I_{1 a}=0, \tau_{a}=\tau_{a 0}(N), \sqrt{I_{2 a}}=\tau_{a 0}(N) \\
& A_{2}=1 / \tau_{a 0}(N)
\end{aligned}
$$

- the parameter $D_{2}$ was determined by means of the axial S-N curve $\sigma_{a 0}(N)$

$$
\begin{aligned}
& \sqrt{I_{2 m}}=0, \tau_{a}=\sigma_{m}=\tau_{m}=0, I_{1 m}=0, \sigma_{a}=\sigma_{a 0}(N), \sqrt{I_{2 a}}=\frac{1}{\sqrt{3}} \sigma_{a 0}(N), I_{1 a}=\sigma_{a 0}(N) \\
& D_{2}=\frac{1-\frac{1}{\sqrt{3}} A_{2} \sigma_{a 0}(N)}{\sigma_{a 0}(N)}
\end{aligned}
$$

the parameter $B_{2}$ was determined by means of the axial S-N curve $\sigma_{a \tau}(N)$ with torsional mean stress $\tau_{\mathrm{m}}=126 \mathrm{MPa}$

$$
\begin{aligned}
& \tau_{a}=\sigma_{m}=0, \sqrt{I_{2 m}}=\tau_{m}, I_{1 m}=0, \sigma_{a}=\sigma_{a \tau}(N), I_{1 a}=\sigma_{a \tau}(N), \sqrt{I_{2 a}}=\frac{1}{\sqrt{3}} \sigma_{a \tau}(N) \\
& B_{2}=\frac{\sqrt{\left(1-D_{2} \sigma_{a \tau}(N)\right)^{2}-\left(\frac{1}{\sqrt{3}} A_{2} \sigma_{a \tau}(N)\right)^{2}}}{\tau_{m}}
\end{aligned}
$$

the parameter $C_{2}$ was determined by means of the torsional S-N curve $\tau_{a \sigma}(\mathrm{N})$ with tensile mean stress $\sigma_{\mathrm{m}}=202 \mathrm{MPa}$

$$
\begin{aligned}
& \sigma_{a}=\tau_{m}=0, \sqrt{I_{2 m}}=\frac{1}{\sqrt{3}} \sigma_{m}, I_{1 m}=\sigma_{m}, I_{1 a}=0, \tau_{a}=\tau_{a \sigma}(N), \sqrt{I_{2 a}}=\tau_{a \sigma}(N) \\
& C_{2}=\frac{1-\sqrt{\left(A_{2} \tau_{a \sigma}(N)\right)^{2}+\left(\frac{1}{\sqrt{3}} B_{2} \sigma_{m}\right)^{2}}}{\sigma_{m}}
\end{aligned}
$$

Thus, the approach presented above has all the advantages of the previous model and allows taking into account the different slopes of the fatigue curves under tension-compression and torsion, however, it requires even more experimental data (four S-N curves $\tau_{a 0}(N), \quad \tau_{a \sigma}(N), \sigma_{a 0}(N)$ and $\left.\sigma_{a \tau}(N)\right)$. 


\section{THE COMPARISON OF THE METHODS GIVEN IN THE ARTICLE}

$\mathrm{I}$

n order to estimate the predictive ability of the models, we assume that the experimental data scatters are approximately the same in logarithmic coordinates with respect to the fatigue life $N$ (that is, the variance of reproducibility are uniform throughout the factor space). In general, it does not contradict the available data. The increase of the fatigue life $N$ leads to the increase of the experimental data scatter, however, in the logarithmic coordinates they remain the same.

Then one can use the following functional to assess the predictive ability of the models:

$$
\Phi_{2}=\frac{1}{n} \sum_{i=1}^{n}\left(\log N_{M i} / N_{i}\right)^{2}
$$

where $N$ is the experimental fatigue life, $N_{M}$ is the model' $\mathrm{s}$ fatigue life, $n$ is the number of the experiments (62 specimens). Tab. 3 shows the values of the functionals for different models. Adjusting experiments are the experiments necessary to determine models parameters. Fig. 2-5 present a comparison of the models with the experimental data.

\begin{tabular}{cccc}
\hline No. & Model & Adjusting experiments & $\Phi$ \\
1 & Marin & - the ultimate tensile strength $\sigma_{u} ;$ & 0.135 \\
2 & Crossland + & - S-N curve $\sigma_{a 0}(N)$. & 0.135 \\
3 & Sines + & $-S-N$ curves $\sigma_{a 0}(N), \tau_{a 0}(N), \sigma_{a \tau}(N)$. & 0.056 \\
4 & Sines++ & $-S-N$ curves $\sigma_{a 0}(N), \tau_{a \sigma}(N), \sigma_{a \tau}(N)$. & 0.025 \\
\hline
\end{tabular}

Table 3: The comparison of the models based on $\Phi$ functional.

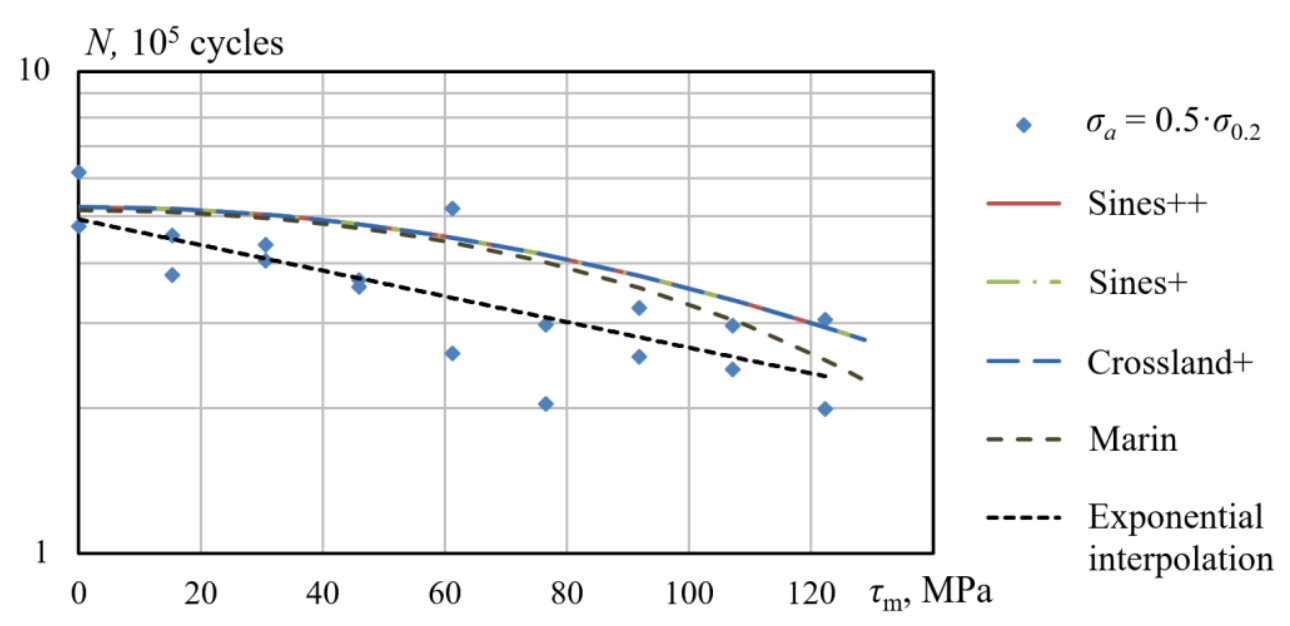

Figure 2: Dependences of fatigue life $N$ of 2024 alloy under cyclic tension-compression with the amplitude $\sigma_{a}=0.5 \cdot \sigma_{y}$ versus the torsional mean stresses $\tau_{\mathrm{m}}$ plotted by means of the multiaxial fatigue models (Marin, Crossland+, Sines + , Sines ++ ).

Based on Fig. 2-5 one may notice that the modified methods of Sines and Crossland predict the same result (the curves coincide). An increase of the mean stress in torsion direction virtually does not affect fatigue strength under the amplitude $\sigma_{a}=0.61 \cdot \sigma_{y}$ (Fig 3) unlike the amplitude $\sigma_{a}=0.5 \cdot \sigma_{y}$ (Fig 2). It is also clear from Tab. 3 and Fig. $2-5$ that Model No. 4 (Sines ++ ) is the most accurate. Finally, one should mention that the number of the experiments carried out with the same loading parameters were not enough to explicitly judge about the model adequacy. It is necessary to increase the amount of the statistical data. 


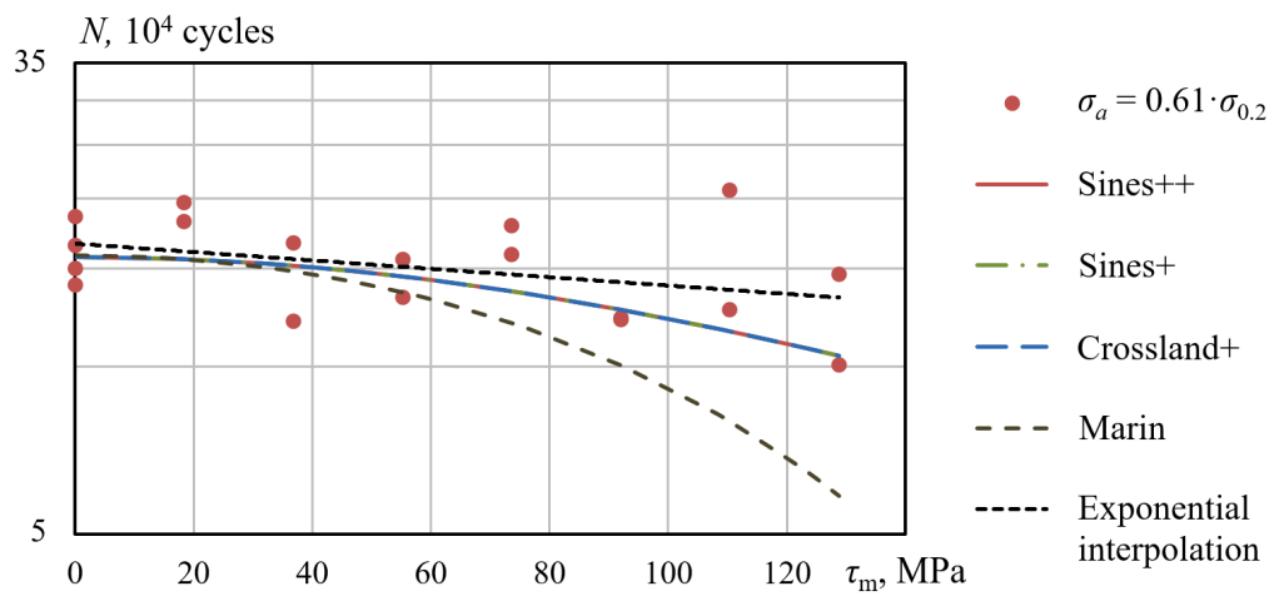

Figure 3: Dependences of fatigue life $N$ of 2024 alloy under under cyclic tension-compression with the amplitude $\sigma_{a}=0.61 \cdot \sigma_{y}$ versus the torsional mean stresses $\tau_{\mathrm{m}}$ plotted by means of the multiaxial fatigue models (Marin, Crossland + , Sines + , Sines ++ ).

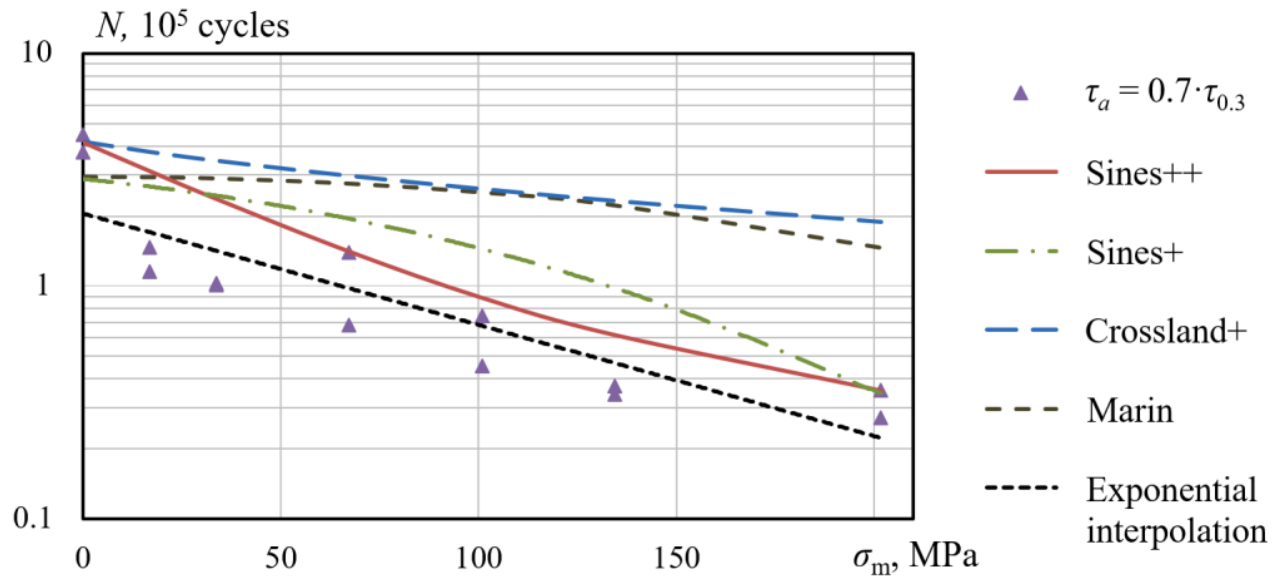

Figure 4: Dependences of fatigue life $N$ of 2024 alloy under cyclic torsion with the amplitude $\tau_{a}=0.7 \cdot \tau_{y}$ versus the tensile mean stresses $\sigma \mathrm{m}$ plotted by means of the multiaxial fatigue models (Marin, Crossland + , Sines + , Sines ++ ).

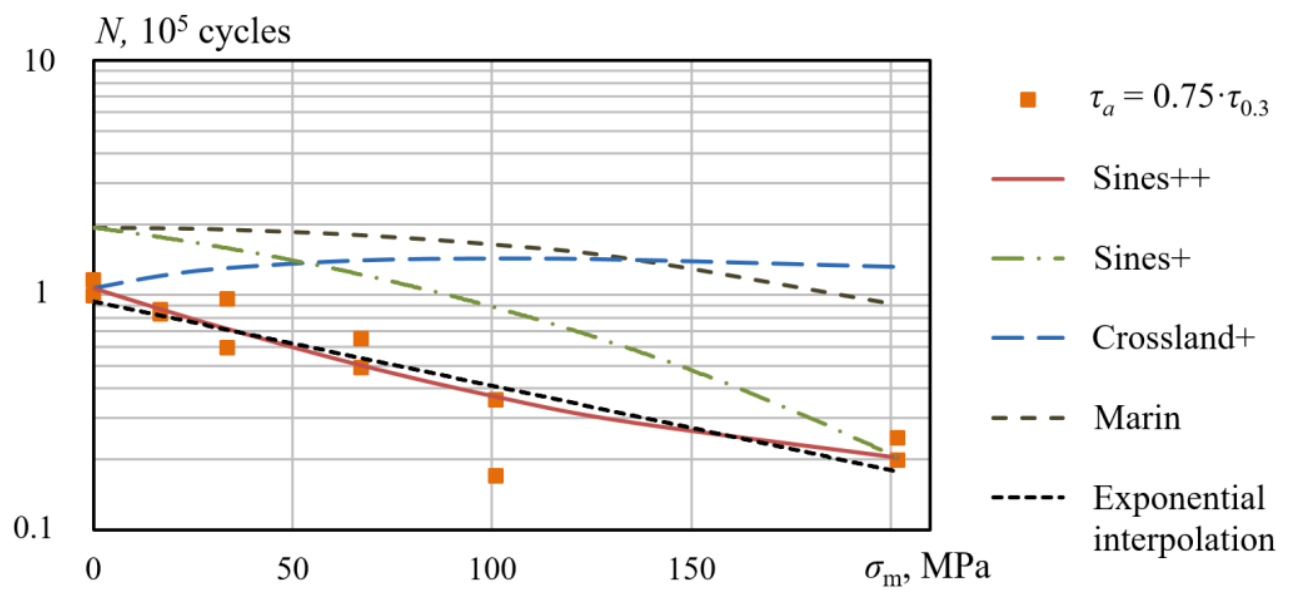

Figure 5: Dependences of fatigue life $N$ of 2024 alloy under cyclic torsion with the amplitude $\tau_{a}=0.75 \cdot \tau_{y}$ versus the tensile mean stresses $\sigma_{\mathrm{m}}$ plotted by means of the multiaxial fatigue models (Marin, Crossland + , Sines + , Sines ++ ). 


\section{CONCLUSIONS}

B

ased on the analysis of the available experimental data the performed work made it possible to reveal the influence of the constant static stresses on the fatigue life of 2024 aluminum alloy during the tension with torsion experiments of the hourglass specimens. At the same time, the implemented values of the constant static stresses did not exceed the corresponding values of the conventional yield strength of the material in question. Some methods of the multiaxial fatigue available in the scientific literature are analyzed; they allow to take into account the patterns of the fatigue behavior noted above. The two modifications of Sines multiaxial fatigue model (Sines + and Sines ++ ) are proposed. According to the comparison results of Marin method and the modified Crossland + , Sines + and Sines ++ methods, the latter (Sines ++ ) describes the experimental data in the most accurate way. The obtained results may be used for strength computations with regard to setting the admissible limits of the constant static stresses occurring in constructions that will not reduce durability of products operated under cyclic loading.

\section{ACKNOWLEDGEMENTS}

he work was carried out in Perm National Research Polytechnic University with the financial support of the Russian Foundation for Basic Research (grants 19-01-00555 A and 16-01-00239 A).

The experimental studies were conducted within the State Assignment of the Ministry of Education and Science of the Russian Federation (9.7529.2017/9.10).

\section{NOMENCLATURE}

E modulus of elasticity

G shear modulus

$\sigma_{y} \quad$ tensile yield strength $(0.2 \%)$

$\sigma_{m} \quad$ tensile mean stress

$\sigma_{a} \quad$ normal stress amplitude

$\sigma_{u} \quad$ ultimate tensile strength

$\sigma_{-1} \quad$ fully reversed axial fatigue limit

$\sigma_{a 0(N)} \quad$ axial S-N curve $\left(R_{\sigma}=-1\right)$

$\sigma_{a \tau(\mathrm{N})} \quad$ axial S-N curve with torsional mean stress $\left(\tau_{m}=126 \mathrm{MPa}\right)$

$\tau_{y} \quad$ torsional yield strength $(0.3 \%)$

$\tau_{m} \quad$ torsional mean stress

$\tau_{a} \quad$ shear stress amplitude

$\tau_{a 0(\mathrm{~N})} \quad$ torsional S-N curve $\left(\mathrm{R}_{\tau}=-1\right)$

$\tau_{a \sigma(\mathrm{N})} \quad$ torsional S-N curve with tensile mean stress $\left(\sigma_{m}=202 \mathrm{MPa}\right)$

$\mathrm{R}_{\sigma} \quad$ axial stress ratio, $\mathrm{R}_{\sigma}=\sigma_{\min } / \sigma_{\max }$

$R_{\tau} \quad$ shear stress ratio, $R_{\tau}=\tau_{\min } / \tau_{\max }$

$N \quad$ fatigue life (number of cycles to failure)

$I_{2} \quad$ second invariant of the stress deviator tensor

$I_{1} \quad$ first invariant of the stress tensor

$\sigma_{H} \quad$ hydrostatic stress

\section{REFERENCES}

[1] Serensen, S.V. (1985). Fatigue of materials and structural elements, Kiev, Naukova dumka.

[2] Troshhenko, V.T. and Sosnovskij, L.A. (1987). Fatigue resistance of metals and alloys, Kiev, Naukova Dumka.

[3] Terentev, V.F. and Korableva, S.A. (2015) Metal fatigue, Moscow, Nauka.

[4] Matvienko, Yu.G. (2006). Models and criteria for fracture mechanics, Moscow, Fizmatlit. 
[5] Sines, G. (1955). Failure of materials under combined repeated stresses with superimposed static stress, Washington, National Advisory Committee for Aeronautics (N.A.C.A).

[6] Hor, A., Saintier, N., Camille, R., Palin-Luc T. and Morel, F. (2014) Statistical assessment of multiaxial HCF criteria at the grain scale, Int. J. Fatigue, 67, pp. 151-158. DOI: 10.1016/j.ijfatigue.2014.01.024.

[7] Saintier, N., Palin-Luc, T., Benabes, J. and Cocheteux, F. (2013) Non-local energy based fatigue life calculation method under multiaxial variable amplitude loadings, Int. J. Fatigue, 54, pp. 68-83. DOI: 10.1016/j.ijfatigue.2012.12.013.

[8] Kluger, K. and Lagoda, T. (2014). New energy model for fatigue life determination under multiaxial loading with different mean values, Int. J. Fatigue, 66, pp. 229-245. DOI: 10.1016/j.ijfatigue.2014.04.008.

[9] Susmel, L. (2014). Four stress analysis strategies to use the Modified Wohler Curve Method to perform the fatigue assessment of weldments subjected to constant and variable amplitude multiaxial fatigue loading, Int. J. Fatigue, 67, pp. 38-54. DOI: 10.1016/j.ijfatigue.2013.12.001.

[10] Anes, V., Reis, L., Li, B., Fonte, M. and De Freitas, M. (2014). New approach for analysis of complex multiaxial loading paths, Int. J. Fatigue, 62, pp. 21-33. DOI: 10.1016/j.ijfatigue.2013.05.004.

[11] Reis, L., Li, B. and De Freitas, M. (2009). Crack initiation and growth path under multiaxial fatigue loading in structural steels, Int. J. Fatigue, 31, pp. 1660-1668. DOI: 10.1016/j.ijfatigue.2009.01.013.

[12] Golub, V.P. (2014). To solving problems of fatigue under biaxial combined loading based on classical fracture criteria, Vestnik dvigatelestroeniya, 2, pp.139-146.

[13] Burago, N.G., Zhuravlev, A.B. and Nikitin, I.S. (2011). Models of multiaxial fatigue fracture and service life estimation of structural elements, Mech. of Solids, 6, pp. 828-838. DOI: 10.3103/S0025654411060033.

[14] Burago, N.G., Zhuravlev, A.B. and Nikitin, I.S. (2013). Very-high-cycle fatigue facture of titanium compressor disks. PNRPU Mech. Bull., 1, pp.52-67.

[15] Shanyavskiy, A.A. (2018). Equivalent Uniaxial Cyclic Tensile Stress as an Energy Characteristic of Metal Fatigue under Multiparameter Loading. Phys. Mesomech., 21(6), pp. 483-491. DOI: 10.1134/S1029959918060024.

[16] Anes, V., Reis, L. and De Freitas, M. (2015). Asynchronous multiaxial fatigue damage evaluation. Proc. Engineering, 101, pp. 421-429. DOI: 10.1016/j.proeng.2015.02.051.

[17] Anes, V., Reis, L. and De Freitas, M. (2015). Multiaxial fatigue damage accumulation under variable amplitude loading conditions. Proc. Engineering, 101, pp. 117-125. DOI: 10.1016/j.proeng.2015.02.016.

[18] Marciniak, Z., Rozumek, D. and Macha, E. (2008). Fatigue lives of 18G2A and 10HNAP steels under variable amplitude and random non-proportional bending with torsion loading, Int. J. Fatigue, 30(5), pp. 800-813.

DOI: 10.1016/j.ijfatigue.2007.07.001.

[19] Shamsei, N., Gladskyi, M., Panasovskyi, K., Shukaev, S. and Fatemi, A. (2010). Multiaxial fatigue of titanium including step loading and load path alteration and sequence effects, Int. J. Fatigue, 32(11), pp. 1862-1874.

DOI: 10.1016/j.ijfatigue.2010.05.006.

[20] Xia, T. and Yao, W. (2013). Comparative research on the accumulative damage rules under multiaxial block loading spectrum for 2024-T4 aluminum alloy, Int. J. Fatigue, 48, pp. 257-265. DOI: 10.1016/j.ijfatigue.2012.11.004.

[21] Sonsino, C.M., Kueppers, M., Eibl, M. and Zhang, G. (2006). Fatigue strength of laser beam welded thin steel structures under multiaxial loading, Int. J. Fatigue, 28(5-6), pp. 657-662. DOI: 10.1016/j.ijfatigue.2005.09.013.

[22] Susmel, L. and Askes, H. (2012). Modified Wohler Curve Method and multiaxial fatigue assessment of thin welded joints, Int. J. Fatigue, 43, pp. 30-42. DOI: 10.1016/j.ijfatigue.2012.01.026.

[23] Li, J., Zhang, Z., Sun, Q. and Li, C. (2011). Multiaxial fatigue life prediction for various metallic materials based on the critical plane approach, Int. J. Fatigue, 33(2), pp. 90-101. DOI: 10.1016/j.ijfatigue.2010.07.003.

[24] Gates, N. and Fatemi, A. (2014). Notched fatigue behavior and stress analysis under multiaxial states of stress, Int. J. Fatigue, 67, pp. 2-14. DOI: 10.1016/j.ijfatigue.2014.01.014.

[25] Gerber, H. (1874). Bestimmung der zulassigen Spannungen in Eisenkonstructionen. Z. Bayerischen Architeckten Ingenieur-Vereins, 6, pp. 101-110.

[26] Goodman, J. (1899). Mechanics Applied to Engineering, London, UK, Longmans Green.

[27] Morrow, J. (1968). Fatigue properties of metals, Section 3.2, In Fatigue Design Handbook, Pub. No. AE-4, PA, USA, SAE: Warrendale.

[28] Smith, J.O. (1942). The effect of range of stress on the fatigue strength of metals, University of Illinois Engineering Experiment Station, Bulletin series, 334.

[29] Oding, I.A. (1935). Prochnost' metallov: Metallovedenie [Metal strength: Metallurgy], L., ONTI NKTP. 
[30] Birger, I.A. (1979). Raschet na prochnost' detalej mashin: Spravochnik [Calculation of the strength of machine parts], M., Mashinostroenie.

[31] Pallarés-Santasmartas, L., Albizuri, J., Avilés, A., Saintier, N. and Merzeau, J. (2018). Influence of mean shear stress on the torsional fatigue behaviour of 34CrNiMo6 steel, Int. J. Fatigue, 113, pp. 54-68. DOI: 10.1016/j.ijfatigue.2018.04.008.

[32] Pallarés-Santasmartas, L.; Albizuri, J.; Avilés, A. and Avilés, R. (2018). Mean Stress Effect on the Axial Fatigue Strength of DIN 34CrNiMo6 Quenched and Tempered Steel, Metals, 8(213). DOI: 10.3390/met8040213.

[33] Mayer, H., Schuller, R., Karr, U., Irrasch, D., Fitzka, M., Hahn, M. and Bacher-Höchst, M. (2015). Cyclic torsion very high cycle fatigue of VDSiCr spring steel at different load ratios, Int. J. Fatigue, 8, pp. 322-327.

DOI: $10.1016 /$ j.ijfatigue.2014.10.007.

[34] Tovo, R., Lazzarin, P., Berto, F., Cova, M. and Maggiolini, E. (2014). Experimental investigation of the multiaxial fatigue strength of ductile cast iron, Theor. Appl. Fract. Mech., 73, pp. 60-67. DOI: 10.1016/j.tafmec.2014.07.003.

[35] Mayer, H., Schuller, R., Karr, U., Fitzka, M., Irrasch, D., Hahn, M. and Bacher-Höchst, M. (2016). Mean stress sensitivity and crack initiation mechanisms of spring steel for torsional and axial VHCF loading, Int. J. Fatigue, 93, pp. 309-317. DOI: $10.1016 / j$. .ijfatigue.2016.04.017.

[36] Bennebach, M. and Palin-Luc, T. (2015). Effect of static and intermittent shear stress on the fatigue strength of notched components under combined rotating bending and torsion, Proc. Engineering, 133, pp. 107-114. DOI: $10.1016 /$ j.proeng.2015.12.635.

[37] Bennebach, M., Palin-Luc, T. and Messager, A. (2018). Effect of mean shear stress on the fatigue strength of notched components under multiaxial stress state. Proc. Engineering, 213, pp. 25-35. DOI: 10.1016/j.proeng.2018.02.004.

[38] Mocilnik, V., Gubeljak, N. and Predan, J. (2017). The Influence of a Static Constant Normal Stress Level on the Fatigue Resistance of High Strength Spring SteelTheor. Appl. Fract. Mech., 91, pp. 139-147.

DOI: $10.1016 /$ j.tafmec.2017.06.002.

[39] Papuga, J., Halama, R. (2018). Mean stress effect in multiaxial fatigue limit criteria. Arch. Appl. Mech., pp. 1-12. DOI: $10.1007 / \mathrm{s} 00419-018-1421-7$.

[40] Wildemann, V.E., Tretyakov, M.P., Staroverov, O.A. and Yankin, A.S. (2018). Influence of the biaxial loading regimes on fatigue life of 2024 aluminum alloy and 40CrMnMo steel, PNRPU Mech. Bull., 4, pp. 169-177.

DOI: $10.15593 /$ perm.mech/2018.4.16.

[41] Crossland, B. (1956). Effect of large hydrostatic pressures on the torsional fatigue strength of an alloy steel, Proc. Int. Conf. Fatigue of Metals, London, pp. 138-149.

[42] Marin, J. (1956). Interpretation of fatigue strengths for combined stresses, pp.184-195. 